\title{
FROM THE MATERIAL TO THE SPIRITUAL IN THE SEA-DRIFT CLUSTER: TRANSCENDENCE IN "ON THE BeAch at Night," "THE WORLD BELOW THE BRINE," AND "ON the Beach at Night Alone"
}

\section{A. James Wohlpart}

SeVERAL CRITICS HAVE SUGgeSTED the central importance of the Sea-Drift cluster to the organic integrity of Leaves of Grass. Thomas Edward Crawley argues in The Structure of "Leaves of Grass" that this cluster, which centers on sea imagery and explores the self, marks a significant change from the first part of the collection, which centers on land and pioneering imagery and explores the "nation's physical boundaries." So what we see is a change from external and material analysis to "introspection [and] self-analysis." ${ }^{1}$ Crawley concludes that "This group of poems, then, effects an important shift in emphasis - from exploration to introspection, from materialism to spiritualism, from individuality to all-inclusive spirituality." Indeed, Crawley continues, this series of eleven poems constitutes "the great awakening of Leaves of Grass."

While other critics may not read the Sea-Drift cluster with the same emphasis on spirituality that lies at the heart of Crawley's analysis, the cluster is, nevertheless, perceived as centrally important to the various themes and issues that Whitman develops throughout Leaves of Grass. ${ }^{3}$ Moreover, the specific poems that comprise the cluster, with Whitman's self-conscious ordering and arrangement, internally develop the major issues of the entire collection. Yet analysis of the cluster has traditionally done one of two things: either centered solely on the first two poems, "Out of the Cradle Endlessly Rocking" and "As I Ebb'ed with the Ocean of Life," or analyzed a few of the shorter lyrics in the collection in a cursory manner, devoting little attention to lengthy and detailed readings of these poems in the context of the cluster and the collection as a whole.

While offering different perspectives on the meaning of specific poems and the relation between specific poems and the continuity of the cluster as a whole, the two readings which have attempted to situate Sea-Drift in the context of Leaves of Grass, the first a detailed article by Robin Riley Fast and the second an article that I wrote, both agree that 
the cluster first questions and then progressively develops the theme of immortality and transcendence. In my own earlier reading, which focused on the relationship between "Out of the Cradle" and the cluster as a whole, I noted that a shift in imagery occurs half way through the cluster from "that of the bird, who teaches the young boy of death and then prepares him for further insights, to that of the ship, which dominates the remainder of the poems in the cluster." The importance of this shift, and the meaning of the ship imagery in the second half of the cluster, is inaugurated in two poems (the fourth and fifth in the eleven poem sequence), "To the Man-of-War-Bird" (a poem which, with its conflation of bird and ship imagery, organically transforms the symbolic focus of the cluster) and "Aboard at a Ship's Helm." The ship imagery is finally and fully developed in the last three poems of the cluster, "Song for All Seas, All Ships," "Patroling Barnegat," and "After the Sea-Ship," where the message of immortality and transcendence is concluded.

Yet between these two groups of poems, with their emphasis on ship imagery, is a group of three poems which appear to represent a unit because of similar concerns and because of the relationship of the titles of the first and third, "On the Beach at Night" (the sixth and middle poem of the cluster), "The World below the Brine," and "On the Beach at Night Alone." Significantly, these poems interrupt what appears to be a smooth transition from bird to ship imagery, from materiality and mortality to spirituality and immortality, in their focus on other images, primarily the beach, the ocean, and the heavens. Indeed, a close and detailed analysis of these three poems will demonstrate the way in which this interruption is paramount to the movement of the entire cluster in that these poems directly describe and define, as opposed to symbolically referring to, the nature of transcendence and immortality.

While the earlier poems, "To the Man-of-War Bird" and "Aboard at a Ship's Helm," present the concept of immortality symbolically, through the image of the ship, "On the Beach at Night," the middle poem in the cluster, engages this concept dramatically, through the presentation of a father discussing a natural scene, the disappearance of the stars in the night sky, with his daughter while they stand on the beach. As in Gerard Manley Hopkins' "Spring and Fall: To a Young Child" where the child watches the falling leaves, exposure to the external scene in "On the Beach at Night" has far-reaching implications in that, ultimately, it allows the child the opportunity to gain a mature awareness of the condition of human beings.

The poem opens with a narrative depiction of the scene and ironically introduces the concept of transcendence with a description of the night sky: 
Up through the darkness,

Amid a transparent clear belt of ether yet left in the east,

Ascends large and calm the lord-star Jupiter,

And nigh at hand, only a very little above,

Swim the delicate sisters the Pleiades. ${ }^{5}$

The planet Jupiter, the largest of the planets in the solar system, is named after the Greek god Zeus, the principle of the Greek and Roman gods who defeated the Titans to become the ruler of the universe. Significantly, the Pleiades are the seven daughters of Atlas, one of the leaders of the Titans, who were placed in the heavens in order to escape the hunter Orion. The juxtaposition of this planet or "lord-star" and this constellation, while apparently suggesting the idea of immortality with its reference to the heavens and to gods, implicitly introduces the idea of mortal limitations and indeed physical procreation. While the Pleiades were placed in the heavens to escape one hunter, they appear here in the poem next to Zeus, who has a propensity towards procreating with mortal women. Such a juxtaposition, rather than pointing to the infinite and immortal nature of these heavenly beings, suggests rather their finite and limited nature.

The suggestion that the stars in the heavens have mortal limitations is, indeed, the child's concern, for, as she stands on the beach looking up to the heavens, the clouds begin to roll in and blot out the night sky: "From the beach the child holding the hand of her father, / Those burial-clouds that lower victorious soon to devour all, / Watching, silently weeps" (11. 11-13). Yet the girl's father reassures her that she need not worry about the stars: "The ravening clouds shall not long be victorious, / They shall not long possess the sky, they devour the stars only in apparition, / Jupiter shall emerge, be patient, watch again another night, the Pleiades shall emerge ..." (11. 17-19). Reinforcing the apparent suggestion that these heavenly bodies indicate transcendence and immortality, the father explains to the girl why she need not weep: "They are immortal, all those stars both silvery and golden shall shine out again, / The great stars and the little ones shall shine out again, they endure, / The vast immortal suns and the long-enduring pensive moons shall again shine" (11. 20-22). In this poem, Whitman sets up a contrast between two competing perspectives, that of the girl who sees the possible limitations of the stars and that of the father who apparently sees beyond these limitations to something infinite. ${ }^{6}$

Yet the father at this point suddenly becomes aware that the child is not merely saddened about the disappearance of the stars but is rather considering her own fate: "Then dearest child mournest thou only for Jupiter? / Considerest thou alone the burial of the stars?" (1l. 23-24). Unlike Hopkins' poem, where the father-figure must explain to the child that her sadness for the loss of the leaves ultimately is a sadness for the 
mortality of human beings, the father-figure here seems to take a clue from his daughter that she is concerned with something beyond the loss of the stars. ${ }^{7}$ With this understanding, the father then, in the last stanza of the poem, hints at the transcendent nature of humanity:

\section{Something there is,}

(With my lips soothing thee, adding I whisper,

I give thee the first suggestion, the problem and indirection,)

Something there is more immortal even than the stars,

(Many the burials, many the days and nights, passing away,)

Something that shall endure longer even than lustrous Jupiter,

Longer than sun or any revolving satellite,

Or the radiant sisters the Pleiades. (11. 25-32)

While the father had previously attempted to reassure his daughter with the promise of the immortal nature of the heavenly bodies, he now admits that these bodies have relative limitations and offers a suggestion that something exists which "is more immortal."

As the father parenthetically notes, embedded in this poem is the "first suggestion, the problem and indirection," that is, the first explanation and description of the transcendence which Whitman points to symbolically in other places in the Sea-Drift cluster with the ship imagery. The father clarifies the nature of this suggestion with reference to two clues that allow us to understand the nature of this problem and why it might be an indirection. The first comes in the father's second parenthetical statement which emphasizes the limited nature of the physical and material: "Many the burials, many the days and nights, passing away." Because of death, the physical world cannot, in and of itself, achieve immortal status. But such an understanding might lead to the mistaken conclusion that immortality should then be sought through physical procreation; yet, as the father notes, there is "Something that shall endure longer even than lustrous Jupiter, / . . / Or the radiant sisters the Pleiades." While the adjectives used to describe Jupiter and the sisters clearly refer to their iredescent nature, they also hint at the lusty nature of Jupiter and the possible results for the Pleiades. Clearly then, physical procreation will not lead to the kind of immortality which concerns Whitman in Leaves of Grass.

"The World below the Brine," the middle poem in this three poem group, reinforces the idea that immortality is not to be sought through physical reproduction and explains how and when transcendence might occur for human beings. Like "On the Beach at Night" (and thus unlike the previous poems with their symbolic reference to ship imagery), "The World below the Brine" begins with a downward focus as the narrator describes the plants and animals that exist on or below the ocean's surface. The poem then apparently contrasts this group of life forms with two other groups: first, human beings "who walk this sphere" and, fi- 
nally, those "who walk other spheres" $(11.10,11)$. While the final two groups are described in only two lines (as opposed to nine lines for the first group), Whitman emphasizes the importance of these concluding lines with the repetition of a key concept at the beginning of each line, the idea of the "change" from the earlier sphere to the last two spheres.

Indeed readings of "The World below the Brine" center on the apparent contrast of the three groups of life forms presented in the poem. Several critics have suggested that such a demarcation affirms Whitman's adherence to the neo-Platonic concept of the Great Chain of Being; through a description of three clearly disparate regions, that below the brine, that in which we live, and that above us, Whitman "indicate[s] that, however difficult, the ascent [of humans to this higher sphere] is nonetheless attainable." Ida Fasel, on the other hand, has claimed that the poem does not refer to neo-Platonic ideals but that it suggests rather Whitman's acceptance of a scientific description of progress, noting that "By mid-nineteenth century the concept of rigid and orderly ascent on temporal and eternal levels had yielded to long, gradual, and demonstrable processes of geological and biological change." Ultimately, for Fasel, the final sphere is not the heavens but rather other planets, a message "not reassuring for transcendental implications."

Even Robin Riley Fast, who situates the poem in the context of the cluster as a whole, argues that the poem in its description of the various spheres "affirms continuity and the prospect of transcendence." 10 Yet "The World below the Brine," like "On the Beach at Night," is not built on continuity and progress but rather on disparity and contrast. While Whitman clearly demarcates three spheres, he actually only describes two very different groups of beings. The first group of life forms, existing in the first sphere, is described in the opening nine lines of the poem as those forms which inhabit the water: the plants which allow "Different colors, pale gray and green, purple, white, and gold ..." and the animals, the "Dumb swimmers ... / Sluggish existences ..." which breathe "that thick breathing air . . ." (11. 5-9). The emphasis in this depiction is on a specific manifestation of the physical and material nature of the lives of those life forms that float or swim in the ocean: "Passions there, wars, pursuits, tribes ..." (1. 9). As with the description of Jupiter and the Pleiades, these plants and animals are limited by their emphasis on the emotions and passions and are thus mortal and stifled (they breathe the "thick breathing air").

The final two lines set up a contrast with the earlier lines in order to further explain the nature of the transcendence that Whitman envisions for human beings. After describing the plants and animals below the brine, the narrator concludes:

The change thence to the sight here, and to the subtle air breathed by beings like us who walk this sphere, 
While clearly these two lines refer to two "beings" who inhabit two different spheres, Whitman suggests a connection between these two groups, and indeed distinguishes them from the swimmers in the earlier lines, with the emphasis that the two groups walk. In the context of the previous poem, "On the Beach at Night," and the movement of the Sea-Drift cluster as a whole, the concluding lines of "The World below the Brine" essentially describe, then, the two possible natures of one life form, human beings.

This poem thus further clarifies Whitman's definition of the transcendent nature of humanity in that it suggests a connection between our physical and material existence on earth and our spiritual existence in a transcendent state. That is, Whitman suggests that, while immortality will not be achieved through physical reproduction, its foundation is the physical. Significantly, "The World below the Brine," a poem which most clearly refers to and thus implicitly defines Whitman's concept of transcendence, has its analogue in Emerson's seminal essay, "Nature." As often noted, Emerson begins his own depiction of this experience with an emphasis on connection to nature: "Crossing a bare common, in snow puddles, at twilight, under a clouded sky, without having in my thoughts any occurrence of special good fortune, I have enjoyed a perfect exhilaration."12 More importantly, Emerson incipiently suggests here that humans, with their heads pointing towards the heavens, attain a transcendent state because of their ability to unite with the cosmos through the use of reason; through connection to nature, he continues, "we return to reason and faith" (p. 10). Such a suggestion is then amplified in the penultimate and concluding section of this passage: "Standing on the bare ground, - my head bathed by the blithe air, and uplifted into infinite space, - all mean egotism vanishes. I become a transparent eye-ball. I am nothing. I see all. The currents of the Universal Being circulate through me; I am part or particle of God" (p. 10). ${ }^{13}$

Whitman adapts Emerson's prose passage in his own poetic description and explanation of transcendence. Unlike the plants and animals who breathe the "thick-breathing air" of the ocean, humans, with their upright stance and thus symbolically their ability to use reason, breathe the "subtle air" of another sphere and are thus capable of transcending onward to yet another sphere: "into infinite space." In addition, the purported final group and sphere is not described in the singular in Whitman's poem but rather in the plural: "of beings who walk other spheres." The enlargement of the transcendent and spiritual state of humanity into multiple beings and spheres again suggests that transcendence will be found through our human nature; indeed, such a magnification of possibilities suggests that achieving this spiritual state 
depends upon differences, upon our individual and unique use of reason as human beings.

The final poem in this grouping, "On the Beach at Night Alone," returns to the dramatic context introduced in "On the Beach at Night." In this third poem, however, the child-daughter has disappeared and the father remains alone ruminating on the meaning of these visions and experiences. As I have already suggested, this group of three poems stands out from the cluster as a whole because it interrupts a smooth transition from bird to ship imagery; yet the group is apparently connected to the first two poems in the cluster, "Out of the Cradle" and "As I Ebb'd," in that it uses a contrast of voices, one mature and wise, the other immature and learning, in order to develop the movement towards transcendence and immortality exemplified in the cluster as a whole. At this point, however, the youthful voice has disappeared and only the mature, experienced voice remains, suggesting that the movement for the boy poet, the "outsetting-bard" described in "Out of the Cradle," is complete and that a fully realized understanding of the mortal and immortal nature of human beings has been attained.

Indeed, "On the Beach at Night Alone" most fully and explicitly defines Whitman's conception of transcendence. In this poem, the father-narrator stands

On the beach at night alone,

As the old mother sways her to and fro singing her husky song,

As I watch the bright stars shining, I think a thought of the clef of the universes and

of the future. (11. 1-3)

The opening not only sets the scene for the final definition of transcendence, of the "clef of the universes and of the future," but also links "On the Beach at Night" and "The World below the Brine" in its reference to the ocean ("the old mother") and the heavens ("the bright stars shining"). Significantly, the penultimate description in this group of poems moves beyond a depiction of the immortal nature of human beings, which insists upon difference, and towards a depiction of the transcendence of all things, which insists upon sameness in difference:

A vast similitude interlocks all,

All spheres, grown, ungrown, small, large, suns, moons, planets,

All distances of place however wide,

All distances of time, all inanimate forms,

All souls, all living bodies though they be ever so different, or in different worlds,

All gaseous, watery, vegetable, mineral processes, the fishes, the brutes,

All nations, colors, barbarisms, civilizations, languages,

All identities that have existed or may exist on this globe, or any globe,

All lives and deaths, all of the past, present, future,

This vast similitude spans them, and always has spann'd,

And shall forever span them and compactly hold and enclose them. (11. 4-14) 
While Whitman maintains the idea of difference, the emphasis throughout is on the way in which these differences are united and compactly held together through a force which has, at its foundation, likeness and resemblance, "A vast similitude interlocks all." 14

Just as "The World below the Brine" has its analogue in the transparent eye-ball passage in Emerson's "Nature," so too does "On the Beach at Night Alone." Indeed, taken together, these two poems develop the Emersonian conception of transcendence, with its emphasis on the ability of humans, through their exercise of reason, to unite with the Over-Soul and thus lose their individuality: "I am nothing. . . . The currents of the Universal Being circulate through me; I am part or particle of God." Just as all of nature is "part or particle of God" (and thus the plants and animals of the sea which had previously been troped as limited and non-transcendent are included in this "vast similitude"), so, too, can humans become a part of God if they use their reason; significantly, such a use of this peculiarly human faculty will allow a new perspective on nature and the world, a perspective which has, at its foundation, the interlocking of all things, human and non-human. ${ }^{15}$

Whitman opens the description of the unity of all things in "The World below the Brine" with a reference to this spiritual essence using an indefinite article: "A vast similitude"; curiously, he then changes this description at the end of the poem by using an adjective: "This vast similitude." At this point, after having concretely discussed, through a dramatic representation, the transcendent experience, the group of three poems is coming to an end and Whitman points outward and onward to the poems that remain in the cluster and even, indeed, in the collection as a whole. The "vast similitude" specifically referred to in this conclusion of "The World below the Brine" is, perhaps, the Sea-Drift cluster and all of the other poems which comprise Leaves of Grass, a collection which attempts to define, individually and uniquely, the nature of each element in the universe while also compactly holding and enclosing them in a single spiritual essence.

\section{University of South Florida}

\section{NOTES}

1 Thomas Edward Crawley, The Structure of "Leaves of Grass" (Austin: University of Texas Press, 1970), 139.

2 Crawley, 110.

3 See, for instance, James E. Miller, Jr., in his Critical Guide to "Leaves of Grass" (Chicago: University of Chicago Press, 1957); Miller's argument centers on the vision of the poet explored in the Sea-Drift cluster and the importance of this vision to the text as a whole. 
4 A. James Wohlpart, "From Outsetting Bard to Mature Poet: Whitman's 'Out of the Cradle' and the Sea-Drift Cluster," Walt Whitman Quarterly Review 9 (Fall 1991), 84. See also Robin Riley Fast, "Structure and Meaning in Whitman's Sea-Drift," American Transcendental Quarterly 53 (Winter 1982), 49-66.

5 Walt Whitman, Leaves of Grass, Sculley Bradley and Harold Blodgett, eds. (New York: Norton, 1973), 11. 4-10. Further references to this text will be noted parenthetically by line numbers.

6 Such a reading of this poem parallels what apparently occurs in earlier poems in the sequence, especially "Out of the Cradle," in that it presents a pair of contrasting voices discussing the nature of humanity and the concept of transcendence. See Wohlpart, "From Outsetting Bard to Mature Poet: Whitman's 'Out of the Cradle' and the SeaDrift Cluster," for a detailed analysis of the competing voices in "Out of the Cradle."

7 Again, such a suggestion about the knowledge of the child would conform to what has occurred in the earlier poems in the cluster, where Whitman has described the growing awareness of the boy-poet as he comes to terms with death and mortality; only as the cluster progresses does the knowledge of immortality become developed.

8 William A. Freedman, "Whitman's 'The World Below the Brine,'" Explicator 23 (1965), Item 39. Robert R. Stillgoe, in "Possible Lockean Influence in 'The World Below the Brine," "Walt Whitman Review 21 (1975), 150-155, presents a slightly more complex and historically contextualized reading which suggests that Whitman's reference to neo-Platonic ideas originates through the ideas of John Locke.

9 Ida Fasel, "Whitman's 'The World Below the Brine,'” Explicator 25 (1966), Item 7.

10 Robin Riley Fast, "Structure and Meaning in Whitman's Sea-Drift," 60.

11 Significantly, scholars have suggested that the impetus for Emerson's essay on "Nature" originated from his visit to the Garden of Plants in Paris where he witnessed natural curiosities and became intrigued with the idea of a sympathetic relation between all life forms (see Douglas Emory Wilson, "Introduction to 'Nature,'" in The Collected Works of Ralph Waldo Emerson [Cambridge: Harvard University Press, 1971], 1:3). Likewise, John R. Stillgoe argues that Whitman's interest in common links, what Stillgoe suggests is at the basis of Whitman's conception of the Great Chain of Being, originated from a similar display by P.T. Barnum ("Possible Lockean Influence in "The World Below the Brine,'” 153-54).

Other seemingly coincidental links exist between these two works. As Wilson notes, "Nature" "was originally conceived as two essays, one looking downward to experience and the other looking upward to truth ... [but was] then welded together . .." (5). Of course "The World below the Brine" is based on a similar design and focus.

12 Ralph Waldo Emerson, "Nature," in The Collected Works of Ralph Waldo Emerson (Cambridge: Harvard University Press, 1971), 1:10. Further references to this text will be noted parenthetically by page number.

13 John Gatta suggests a direct influence between this passage, which describes Emersonian transcendence as an intellectual and spiritual enterprise, and Section 5 of Whitman's "Song of Myself," which describes transcendence ecstatically. Noting the difference in emphasis, Gatta points to Whitman's revision of Emerson: "Whitman could scarcely miss noticing how thoroughly Emerson's epiphany reduces to a cerebral event - an uplifting of the head away and apart from the body. Instead of Whitman's orgasmic, interpenetrative union with the body, a plunging downward from tongue to heart, Emerson records his bodily evaporation" ("Whitman's Re-Vision of Emersonian 
Ecstacy in 'Song of Myself,'" in Joann P. Krieg, ed., Walt Whitman: Here and Now [Westport: Greenwood Press, 1985], 178).

Such a reading develops my own in that "Song of Myself," occurring in the first part of Leaves of Grass, would necessarily describe the transcendent state with an emphasis on the physical and material. Because Sea-Drift inaugurates a shift in the collection as a whole from the physical to the spiritual, Whitman's reference to Emerson's passage in this cluster is oriented less towards the material and more towards the intellectual.

14 This is, of course, the heart of Whitman's message about democracy, that each human being must act as an individual, unique and separate, in order to achieve the unity which makes up an indivisible nation.

15 James Cox notes that the eyeball passage is a description of "an action, a declaration of a change from being into seeing." Moreover, as Cox notes, built into this passage, as in these three poems and the Sea-Drift cluster, is the tension between individuality and unity, between materiality and spirituality: "Since the eyeball is transparent and cannot be seen ... it should be coextensive with the infinite universe. Yet the eyeball metaphor is nonetheless concrete, an assertion of infinite existence in a definite image" ("R.W. Emerson: The Circles of the Eye," in Harold Bloom, ed., Modern Critical Views: Ralph Waldo Emerson [New York: Chelsea House, 1985], 47-48). 